\title{
TREINAMENTO E DESENVOLVIMENTO MOTIVACIONAL
}

Eder Wilker Soares dos Santos, Valdecir Cahoni Rodrigues.

Universidade do Oeste Paulista - UNOESTE, Presidente Prudente, SP. E-mail: eder wilker@hotmail.com

\section{RESUMO}

As empresas modernas reconhecem o valor do capital humano e com isso buscam variadas formas e métodos que estejam focados na melhoria da qualidade deste capital cada vez mais. Com isso, o processo de treinamento e desenvolvimento se torna muito importante dentro da organização. A motivação pode ser um grande aliado da organização no processo do treinamento e desenvolvimento. O objetivo deste estudo foi investigar se a produtividade dos colaboradores está relacionada à motivação emocional e tem relação com o comportamento intrapessoal e o convívio interpessoal. Este estudo foi realizado através de pesquisa bibliográfica e estudo qualitativo. Segundo o estudo, fica manifesto que a motivação pessoal influencia na produtividade e o treinamento e desenvolvimento é eficaz para melhorar essa motivação pessoal e da equipe. Conclui-se que as organizações necessitam da implantação de um processo de treinamento e desenvolvimento motivacional visando todos os setores da empresa e seus respectivos colaboradores.

Palavras-chave: Treinamento. Desenvolvimento. Motivação.

\section{TRAINING AND MOTIVATIONAL DEVELOPMENT}

\begin{abstract}
Modern companies recognize the value of human capital, and in doing so are looking for a variety of ways and methods that are focused on improving the quality of this capital more and more. With this, the training and development process becomes very important within the organization. Motivation can be a great ally of the organization in the training and development process. The objective of this study was to investigate whether employee productivity is related to emotional motivation and is related to intrapersonal behavior and interpersonal conviviality. This study was carried out through bibliographic research and qualitative study. According to the study, it is clear that personal motivation influences productivity and training and development is a way to improve that personal and team motivation. We conclude that organizations need the implementation of a motivational training and development process targeting all sectors of the company and their respective collaborators.
\end{abstract}

Keywords: Training. Development. Motivation.

\section{INTRODUÇÃO}

Algumas empresas contemporâneas reconhecem o valor do capital humano e com isso buscam variadas formas e métodos que estejam focados na melhoria da qualidade deste capital cada vez mais. Com isso, o processo de treinamento e desenvolvimento se torna muito importante dentro da organização. Milkovich e Boudreau (2000) enfatizam não somente a importância da corporação incluir em seus processos o treinamento e desenvolvimento dos colaboradores, como também a importância em mantê-lo, pois asseguram que os resultados serão positivos apenas se este processo for constante.

Através do treinamento o colaborador deixa para trás seu modo de agir, adquirindo novas informações que serão agregadas ao seu dia a dia, desenvolvendo sua capacidade profissional. Este desenvolvimento fortalece, constrói novas habilidades, explora as formas que os talentos contribuem para o todo, além de ampliar a motivação no indivíduo, que é algo extremamente importante para desenvolver a qualidade de sua produtividade em suas atividades laborais. 
Chiavenato (1992) expõe que a motivação está dentro das pessoas, mas também pode e necessita ser entusiasmada por fontes externas à empresa e pelo seu trabalho dentro do ambiente organizacional. Ou seja, a motivação é intrínseca, porém, meios de trabalho extrínseco também podem aperfeiçoar o desenvolvimento motivacional. Por isso, o planejamento estratégico da empresa deve se atentar a treinar e desenvolver a motivação em seus colaboradores. Contudo, para que este processo seja eficiente, é necessária atenção em alguns pontos, conforme Boog (1994) demonstra que o treinamento desenvolvido deve ser imediatamente aplicável, ajustado à realidade da empresa e às suas atuais necessidades, competente na eliminação das necessidades básicas, incentivador do autodesenvolvimento, e, avaliado metodicamente.

Assim, o treinamento sendo aplicado de maneira profissional, torna-se uma ferramenta eficaz que contribui muito para a melhoria contínua na qualidade dos serviços prestados, satisfazendo as expectativas de todos os envolvidos, tanto os gestores quanto os colaboradores.

O objetivo da pesquisa é investigar se a produtividade dos colaboradores está relacionada à motivação emocional e tem relação com o comportamento intrapessoal e o convívio interpessoal. E tem por objetivo específico conceituar Treinamento e Desenvolvimento Motivacional e a motivação e sua influência nas organizações. Justifica-se esta pesquisa uma vez que os resultados podem ajudar o gestor a elaborar meios de melhorar o trabalho em equipe e as relações intrapessoais e interpessoais na empresa.

\section{METODOLOGIA}

Este estudo foi realizado através de pesquisas de coleta de dados de fontes secundárias, sendo por meio de levantamento bibliográfico que segundo Vergara (2009, pg. 43), "é o estudo sistematizado desenvolvido com base em material publicado em livros, revistas, jornais, redes eletrônicas". Portanto, o conteúdo bibliográfico foi coletado em livros e artigos que abordam o tema proposto.

Trata-se também de um estudo qualitativo, visto que segundo Goldenberg (1997), os pesquisadores que empregam os métodos qualitativos buscam explicar o motivo das coisas, não quantificam valores, porque os dados analisados não são medidos e podem ter diferentes abordagens. Assim, a intenção da presente pesquisa é descrever, compreender e explicar as informações pesquisadas.

\section{RESULTADOS}

\subsection{Treinamento e Desenvolvimento}

Um dos principais objetivos de treinar os colaboradores, segundo Carvalho (1993) é mudar as atitudes destes, criando um clima satisfatório no ambiente de trabalho, aumentando a motivação dos mesmos e tornando-os mais receptivos às suas respectivas chefias. Chiavenato (2009, p. 68) define treinamento como:

O processo de ensinar aos empregados habilidades básicas que eles necessitam para desempenhar seus cargos, e desenvolver qualidades nos Recursos Humanos (RH) que os permitam serem mais produtivos e contribuir para a excelência da organização.

Para Wexley (1984) treinamento é um procedimento planejado para tornar a aprendizagem mais fácil para os colaboradores com o intuito de mudar o comportamento estabelecido pelo trabalho.

Goldstein (1991) definiu treinamento como a ampliação de atitudes, conceitos, princípios ou habilidades que brotem durante o processo do desempenho organizacional, obtidos pelo meio de técnicas de ensino e troca de informações e conhecimento.

$\mathrm{O}$ treinamento necessita seguir algumas fases para alcançar o escopo sem que danifique o efeito final da ação. França $(2011$, p. 88) expõe que:

Os processos e as
atividades de treinamento
devem agir de forma
unificada com os outros
instrumentos e atividades
da área de RH, que se
relacionam com o
treinamento. É necessário
existir desde o
recrutamento e seleção,
um processo de
acompanhamento
avaliação;
administração de cargos e


remuneração; controle pessoal; e, administração de benefícios. Dessa forma, para o treinamento também é necessário adotar um conjunto de etapas, que podem ser observados como um método cíclico que está sempre se renovando.

Para Chiavenato (2004, p. 404b),

0 processo de treinamento é bem próximo de um modelo de sistema aberto, e tem como integrantes: a entrada ou inputs, que são os componentes do início do processo, como os treinandos, os recursos organizacionais,

informação, entre outros; o processamento ou throughputs, que são os processos de ensino, a aprendizagem individual, o programa de treinamento; esses processos resultam nas saídas ou outputs que são os pessoais habilitados, os conhecimentos e competências, a eficácia organizacional; e, a última fase é a retroação ou feedback que se compreende na avaliação dos procedimentos $\mathrm{e}$ resultados do treinamento, através de elementos informais ou estudos sistemáticos.

Marras (2011) já discorre que o processo de treinamento utilizado nas empresas passa por quatro fases, que são: o levantamento das necessidades de treinamento (LNT), que é o processo de treinamento que faz a adaptação das ausências existentes entre o que a organização necessita e o que os colaboradores têm a proporcionar; a programação que é a parte do processo que organiza as prioridades entre o necessário e o provável, de acordo com os recursos que a empresa possui; a implementação e/ou execução é responsável pela ação do processo, ou seja, colocar em prática tudo que foi planejado e programado para preencher as carências identificadas no levantamento das necessidades; e, a avaliação dos resultados, que é a última parte do processo e tem por objetivo mensurar os resultados atingidos confrontado ao que foi planejado pela empresa e examinar se atingiu as modificações almejadas no comportamento dos indivíduos. Essas fases, quando são executadas de forma corretas, podem dar resultados significativos para a empresa.

Todo o procedimento de treinamento tem como objetivo aperfeiçoar as competências e habilidades dos sujeitos, e, consequentemente alcançar o êxito profissional e o desenvolvimento da organização. Desta forma, o desenvolvimento é uma consequência do treinamento. Assim como menciona Chiavenato (2014, p.359). "o desenvolvimento organizacional muda atitudes, valores e crenças dos funcionários, para que eles próprios possam identificar e implementar mudanças".

$\mathrm{Na}$ visão de Milkovich e Boudreau (2000, p.338) "desenvolvimento é o processo de longo prazo para aperfeiçoar as capacidades e motivações dos empregados, a fim de torná-los futuros membros valiosos da organização". Marras (2009, p.145) considera o treinamento como "[...] um processo de assimilação da cultura em curto prazo, que objetiva repassar ou reciclar conhecimentos, habilidades ou atitudes relacionadas diretamente à execução de tarefas ou a sua otimização no trabalho".

Minicucci (1995) discorre que o treinamento pode ser um empenho planejado, organizado e projetado para auxiliar os funcionários na ampliação de suas capacidades e de sua motivação. Já Fontes (1980) acredita que a importância do treinamento tem relação com as necessidades da organização e que quando estas necessidades são identificadas, podem ser reduzidas com alguns fatores, como a readaptação profissional e a motivação, que altera o clima organizacional, melhora a disciplina dentro do ambiente organizacional e a qualidade do produto final e consequentemente diminui o absenteísmo e o desperdício de matéria-prima.

\subsection{Motivação}

A motivação pode ser um grande aliado da organização no processo do treinamento e desenvolvimento. Ambas são relacionadas e a motivação é para alguns autores de suma 
importância para a produção e qualidade do produto final.

Conforme Castro, et al. (2002, p. 86), “o processo motivacional individual busca a manutenção do equilíbrio, sendo que a energia usada para este, vem da capacidade de cada um se auto motivar, a qual é desenvolvida ao longo do tempo". Por este motivo a necessidade não só de inserir, como também manter o treinamento e desenvolvimento motivacional dentro da organização.

Heller (1999) dispõe que a arte de motivar um indivíduo começa com o descobrimento de meios que façam com o que o comportamento deste seja influenciado, de modo que aumente consequentemente seus resultados, atingindo assim as metas organizacionais impostas pelas respectivas chefias. É indispensável, portanto, estar atento ao que estimula a motivação. Chiavenato (2010, p.44) revela que "[...] o que motiva alguém hoje pode não motivar amanhã".

Bernardinho (2006, p. 115 e 116), afirma que "a motivação baseia-se em dois pilares: o primeiro deles é a necessidade. Se você precisa, vai 'correr atrás' e se dedicar. O segundo é a paixão. Se você gosta, ama o que faz, vai querer melhorar sempre". Podemos ressaltar que os conceitos acima tratam a motivação como sendo algo intrínseco, ou seja, pessoal e que parte do íntimo do indivíduo.

Porém, existe também a motivação extrínseca relacionada por estímulos ambientais, que vêm de fora para dentro, conforme Chiavenato (1992). Um bom exemplo de motivação extrínseca são benefícios que a empresa oferece ao colaborador, como um plano de qualidade de vida no trabalho, ou um bônus por produtividade, ou até mesmo o treinamento e desenvolvimento de suas habilidades.

Chiavenato (2003) explica que através de teorias já comprovadas por Abraham Maslow e Frederick Herzberg, a motivação influencia totalmente na produtividade dos colaboradores. Além de produzirem com mais qualidade, fortalece o relacionamento interpessoal e ajuda a melhorar a qualidade de vida e o clima organizacional o que colabora também na cultura da empresa e nos lucros obtidos pela mesma.

Robbins (2002, p. 152) expõe com simplicidade o funcionamento da teoria de Maslow: "existe uma hierarquia de cinco necessidades [...] e, à medida que cada uma delas é satisfeita, a seguinte torna-se dominante", ou seja, o indivíduo só passa a sentir a necessidade seguinte quando a anterior tiver sido satisfatoriamente saciada.

No âmbito organizacional, as necessidades fisiológicas motivam seus colaboradores pela necessidade da alimentação, descanso e lazer; a segurança motiva pela estabilidade e necessidade de remuneração; as sociais, pela interação com colegas e o bom clima na empresa; a estima, ser reconhecido como profissional, a oportunidade de uma promoção; e, a auto realização, pela participação nas decisões, autonomia, desafios mais complexos.

A maior diferença entre as teorias de Maslow e a de Herzberg, segundo Chiavenato (2003) é no modo que foi feita a base para os respectivos estudos, enquanto Maslow observou a motivação em relação às necessidades humanas, Herzberg a avaliou ponderando o ambiente externo e os afazeres que do indivíduo na organização.

A teoria de Herzberg foi baseada numa pesquisa cometida por ele mesmo, na qual interrogou diversos colaboradores sobre as condições organizacionais que os deixavam satisfeitos ou insatisfeitos e que estas pessoas expusessem essas ocasiões, e, assim, criou grupos para elaborar seu estudo. Dessa forma, Herzberg verificou que os fatores relacionados às ocasiões de satisfação dos indivíduos com suas atividades são bastante diferentes dos fatores que provocam os períodos de insatisfação. Herzberg acreditava que o fator motivacional mais importante para o empregado está nas suas atividades desempenhadas, pois, crê que a relação do homem com o seu trabalho é básica e que as atitudes adotadas podem refletir em sucesso ou fracasso profissional.

Robbins (2002) alega que Herzberg notou características que continuamente serão associadas à satisfação ou à insatisfação no ambiente organizacional e que os fatores intrínsecos estão pareados à satisfação com o trabalho, ou seja, os entrevistados que se sentiam satisfeitos atribuíam essa qualidade a eles mesmos e não a circunstâncias externas. Já os que se julgavam insatisfeitos indicavam os fatores externos, como exemplo, chefias, remuneração, condições de trabalhistas, como os responsáveis por seus descontentamentos.

Chiavenato (1987) explica que a satisfação nas atividades laborais que ocupa na organização é decorrente das atividades que incitam ou estimulam o colaborador, são os 
denominados fatores motivacionais. A insatisfação é relacionada à realidade da empresa, como o ambiente de trabalho, o clima organizacional, a relação interpessoal, estes são os chamados fatores higiênicos.

O estudo dessas teorias é importante, visto que Chiavenato (2004a) alega que são facilmente aplicadas dentro do âmbito organizacional e que a motivação é essencial dentro das corporações, pois um indivíduo motivado tende a alcançar as metas organizacionais e melhorar sua produtividade nas suas tarefas desempenhadas. Assim, é fundamental que as organizações estimulem o exercício de treinamento como fator motivacional.

Além deste estímulo ao treinamento, é necessário também adequar o ambiente para motivar as equipes, como por exemplo, são necessárias condições de trabalho apropriadas, pois os funcionários não se sentem motivados nem prestigiados quando não tem os materiais para trabalhar eficientemente. Importante também um clima organizacional agradável, pois não há como motivar um colaborador em meio a um espaço desagradável, no qual ele não se sinta bem. Outro ponto são os programas de incentivos, como prêmios pelo atingimento de metas, bônus de performance anual, entre outros. Somado a estes programas, é interessante ter uma remuneração que faça jus ao trabalho executado e a responsabilidade empregada pelo indivíduo, além de um bom pacote de benefícios, como o ticket alimentação e plano de saúde.

Existem outros pontos que também corroboram para a motivação dos colaboradores, como a inclusão da equipe nas decisões para que esta se sinta parte da empresa. O feedback também tem um papel muito importante, pois além de direcionar o indivíduo e a equipe no que precisariam melhorar e no que estão indo bem, estes também se sentem prestigiados e notados pelo seu líder. O feedback também é uma ferramenta para o desenvolvimento do colaborador, e, para essa ferramenta funcionar, é importante uma avaliação de desempenho bem estruturada.

Igualmente aos fatores acima, também é interessante promover comemorações e convenções, como festas de fim de ano, que, por exemplo, ajuda no entrosamento da equipe de forma descontraída, visto que estes que trabalham em conjunto. Quando a equipe tem uma harmonia e entrosamento, produz mais e com mais qualidade. $E$, também é necessário que - colaborador tenha uma perspectiva de crescimento, pois quando este percebe que tem chance de crescer na empresa, se compromete mais com a corporação e com a sua equipe, dessa forma, é interessante que exista um programa de cargos e salários.

\section{DISCUSSÃO OU CONCLUSÃO}

Foi possível verificar que a motivação é importante para o treinamento e desenvolvimento organizacional. Segundo o estudo, fica manifesto que a motivação pessoal influencia na produtividade. Observa-se que motivação é essencial dentro das corporações. A mesma é influenciada tanto por fatores internos quanto externos à organização, mas existem meios desta fazer com que busque nos seus colaboradores o seu potencial para ter uma equipe integrada que busquem o mesmo objetivo e vistam a camisa da empresa.

Segundo a teoria de Herzberg os fatores externos são os que mais influenciam os colaboradores, como os líderes, o ambiente organizacional, o reconhecimento, entre outros. Visto isso, a motivação emocional tem relação com o comportamento intrapessoal e o convívio interpessoal, sendo de suma importância que a organização prese por um bom ambiente de trabalho, com qualidade de vida e diversos fatores que contribuam para que essa motivação ocorra e traga bons resultados.

Um colaborador comprometido com o seu trabalho é elemento de anseio de qualquer empresa, porque valoriza o que faz, sente-se responsável por obter os melhores resultados e um bom desempenho. Marras (2011) cita algumas benfeitorias proporcionadas pelo treinamento e desenvolvimento motivacional, entre entes, o aumento da produtividade, aumento das habilidades, melhoria no clima organizacional, aumento da motivação pessoal, melhoria na qualidade dos resultados, entre outros.

Assim, conclui-se de acordo com a pesquisa que as organizações necessitam da implantação de um processo de treinamento e desenvolvimento motivacional visando todos os setores e seus respectivos colaboradores. Pois, ficou evidente que a motivação emocional, intrapessoal e o relacionamento interpessoal são alguns dos fatores que mais repercutem e geram resultados nos indivíduos. E, desta forma, é 
importante que a empresa inteira participe deste processo.

\section{REFERÊNCIAS}

BERNARDINHO. Transformando suor em ouro. Rio de Janeiro: Sextante, 2006.

BOOG, G. G. Manual de treinamento e desenvolvimento. 2. ed. São Paulo: Makron Books, 1994.

CASTRO, A. P. et al. Manual de gestão de pessoas e equipes: estratégias e tendências. 1. ed. São Paulo: Editora Gente, 2002.

CARVALHO, A. V. Administração de recursos humanos. São Paulo: Pioneira, 1993.

CHIAVENATO, I. Administração de recursos humanos: fundamentos básicos. 5. ed. São Paulo: Atlas, 2003.

CHIAVENATO, I. Administração nos novos tempos. 2.ed. Rio de Janeiro: Campus, 2004a.

CHIAVENATO, I. Administração: teoria, processo e prática. 2. ed. São Paulo: McGraw-Hill, 1987.

CHIAVENATO, I. Comportamento Organizacional, a dinâmica do sucesso das organizações. 2. ed. Rio de Janeiro: Editora Elsevier, 2010.

CHIAVENATO, I. Gerenciando pessoas: o passo decisivo para a administração participativa. 3. ed. São Paulo: Makron Books, 1992.

CHIAVENATO, I. Gestão de Pessoas: o novo papel dos recursos humanos nas organizações. 4. ed. São Paulo: Manoele, 2014.

CHIAVENATO, I. Introdução à teoria geral da administração. 7 . ed. Rio de Janeiro: Elsevier, 2004b.

CHIAVENATO, I. Treinamento e desenvolvimento de recursos humanos: como incrementar talentos na empresa. 7. ed. São Paulo: Manole, 2009.

FONTES, L. B. Manual do treinamento na empresa moderna. 4. ed. São Paulo: Atlas, 1980.
FRANÇA, A. C. L. Práticas de recursos humanos PRH: conceitos, ferramentas e procedimentos. 1. ed. São Paulo: Atlas, 2011.

GOLDENBERG, M. A arte de pesquisar: como fazer pesquisa qualitativa em Ciências Sociais. Rio de Janeiro: Record, 1997.

GOLDSTEIN, I. L. Training in work organizations. In: DUNNET; HOUGH (Orgs). Handbook of industrial and organizational psychology. 2. ed. California: Consulting Psychology Press, 1991. p. 507-619.

HELLER, R. Como motivar pessoas. São Paulo: Publifolha, 1999.

MARRAS, J. P. Administração de recursos humanos. 13. ed. São Paulo: Saraiva, 2009.

MARRAS, J. P. Administração de recursos humanos: do operacional ao estratégico. 14. ed. São Paulo: Saraiva, 2011.

MILKOVICH, G. T.; BOUDREAU, J. W. Administração de recursos humanos. 1. ed. São Paulo: Atlas, 2000.

MINICUCCI, A. Psicologia aplicada à administração. 5. ed. São Paulo: Atlas, 1995.

ROBBINS, S. P. Comportamento organizacional. 9. ed. São Paulo: Person Education: Prentice Hall, 2002.

VERGARA, S. C. Projetos e Relatórios de Pesquisa em Administração. 10. ed. São Paulo: Atlas, 2009.

WEXLEY, K. N. Personnel training. Annual Review of Psychology. v. 35, p. 519-51, 1984. https://doi.org/10.1146/annurev.ps.35.020184.0 $\underline{02511}$

Recebido para publicação em 15/11/2017

Revisado em 23/01/2019

Aceito em 10/03/2019 